\title{
Dipeptidyl Peptidase Inhibitors: A New Step Towards Normoglycemia
}

\author{
Alexandre Fredenrich*, Stéphanie Pallé, Bertrand Canivet
}

Pasteur Hospital, Department of Diabetology, Nice, F-06002, France

\begin{abstract}
Current medical therapy of type 2 diabetes use drugs targeting either insulin resistance, as metformin and/or glitazones, or insulin secretion, as sulfonylureas or glinides. The incretin effect, mainly due to glucagon-like peptide 1 (GLP-1), enhances the post-meal secretion of insulin, but its potential pharmacological use is hampered by the very short half-life of GLP-1. The inhibition of dipeptidyl peptidase-4 (DPP-4), which inactivates GLP-1, has led to the development of a new class of antidiabetic molecules, the DPP-4 inhibitors, also known as gliptins. Sitagliptin is now commercially available, but many other gliptins are currently under clinical development. Their normoglycemic efficacy is moderate, with a mean $\mathrm{HbA} 1 \mathrm{c}$ decrease by 0.7 to $1.1 \%$, and they are well-tolerated, especially with a low risk of hypoglycaemia and no weight gain. In animal studies, they appear to preserve pancreatic $\beta$-cell function, by increasing $\beta$ cell mass and reducing apoptosis. The clinical significance of these properties requires confirmation by further long-term studies. DPP-4 inhibitors seem to represent an efficient and well-tolerated new class of oral normoglycaemic agents, with a potential beneficial effect on pancreatic function, but their real efficacy and safety have to be firmly assessed in the future, before they could find their appropriate place in the management of type 2 diabetes.
\end{abstract}

Keywords: Dipeptidyl peptidase-4 inhibitors, incretin, metformin, sitagliptin, type 2 diabetes, vildagliptin.

\section{INTRODUCTION}

The burden of type 2 diabetes is rapidly rising throughout the world, and this will undoubtedly dramatically increase morbidity and mortality due to micro- and macrovascular complications. This evolution is due not only to genetic predisposition, but mainly to contemporary lifestyle which favours sedentarity and abundance of high-fat and highcarbohydrate diet. Homeostasis of blood glucose level is maintained through balanced secretion of insulin and glucagon, synthesized respectively by $\beta$ and $\alpha$ cells of the pancreatic islets. Pathophysiology of type 2 diabetes is characterized by a combination of insulin resistance and failure of insulin secretion. At early stage of the disease and even before, in the prediabetic state, insulin resistance is the predominant abnormality, but it is compensated by an increase in insulin secretion, in order to keep glycaemia in the normal range. As time goes by, this compensation disappears because insulin secretion begins to fail, which leads to overt diabetes. To date, main available oral antidiabetic medications target either insulin resistance (metformin, glitazones), or insulin deficiency (sulfonylureas, glinides). A new approach is the use of agents that enhance the physiological activities of gut-derived hormones known as incretins.

\section{The Incretin Effect (Fig. 1A)}

After glucose intake, the secretion of insulin varies depending on the route of glucose administration. Oral glucose provides a more potent insulinotropic stimulus compared with isoglycaemic intravenous challenge. This finding is known as incretin effect [1] and is mainly due to

*Address correspondence to this author at the Department of Diabetology, Pasteur Hospital, F-06002 Nice, France; Tel: + 33492037 721;

Fax: + 33492038 485; E-mail: fredenrich.a@chu-nice.fr two peptides, GIP (glucose-dependent insulinotropic peptide, formerly known as gastric inhibitory peptide), and GLP1 (glucagon-like peptide-1), which seems to be responsible for the major part of incretin effect on $\beta$-cell function [2] and hence has become the favourite potential therapeutic candidate. Moreover, diabetic patients appear to be resistant to GIP while they have reduced GLP1 secretion but normal responsiveness to the hormone. GLP1 enhances insulin secretion only when glucose level rises above $5 \mathrm{mmol} / 1$ [3]. Incretins have no longer insulinotropic effect when blood glucose level decreases below $3 \mathrm{mmol} / \mathrm{l}$.

GLP1 is a 37 aminoacid polypeptide secreted in L-type endocrine cells of the distal ileum and colon. A meal rich in fat and carbohydrates is the main physiological stimulus for GLP1 secretion. It is released into the circulation quickly after oral ingestion, in a biphasic pattern (early phase within 10 to $15 \mathrm{mn}$, and second phase within 30 to $60 \mathrm{mn}$ ). The early release is likely to be mediated by autonomic nervous system, by neurotransmitters as acetylcholine, and by GIP. Conversely the second phase of GLP1 secretion is mediated by direct contact of nutrients with the L cells [4]. In humans, major part of circulating GLP1 is GLP1(7-36) amide.

The circulating level of GLP1 is rapidly decreasing after secretion (half-life $<2 \mathrm{~min}$ ) because of enzymatic inactivation mainly due to dipeptidyl-peptidase 4 (DPP-4), which cleaves GLP1 into the inactive form GLP1(9-36) amide.

Consequently, as inhibition of DPP-4 increases the halflife of incretins, it has become a new target in the development of normoglycaemic molecules.

\section{Enzyme Dipeptidyl Peptidase 4}

DPP-4 is an ubiquitous enzyme, broadly found in numerous tissues, which belongs to the serine protease family. It is also found in vascular endothelial cells and 
(A)

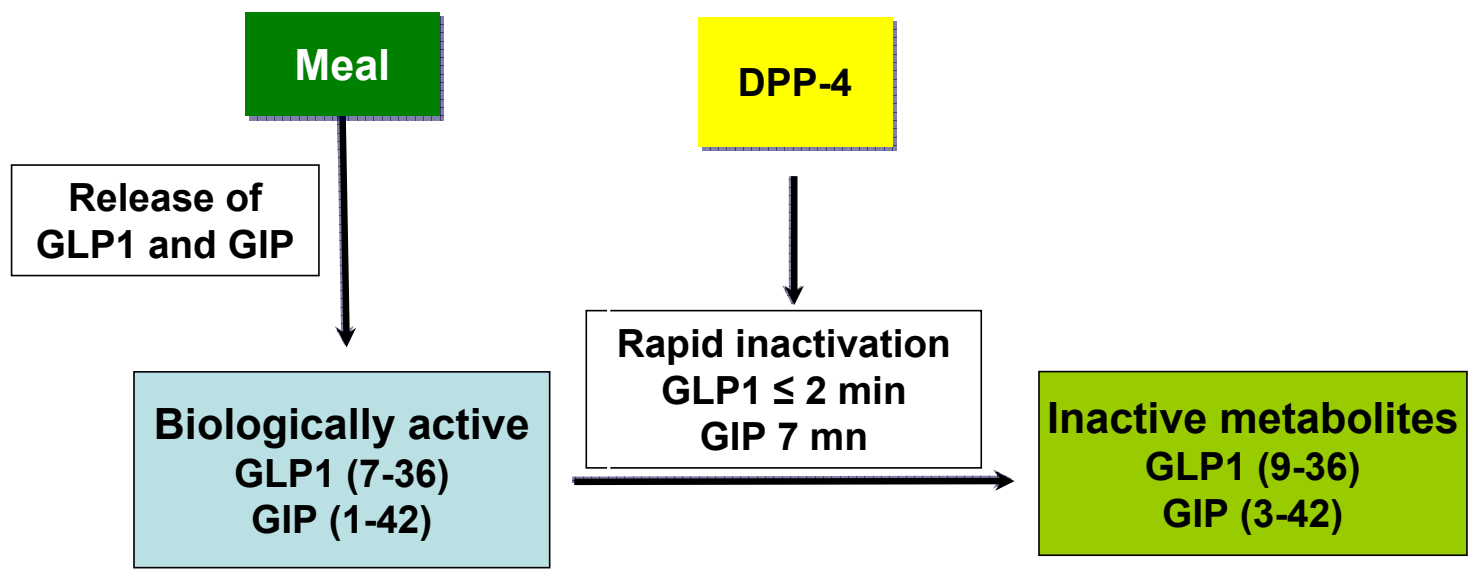

Adapted from : Deacon CF, et al. Diabetes 1995; 44:1126-31; Kieffer TJ, et al. Endocrinology 1995; 136: 3585-96; Ahren B. Curr Diab Rep 2003; 3: 365-72; Deacon CF, et al. J Clin Endocrinol Metab 1995; 80 : 952-7; Weber AE. J Med Chem 2004; 47: 4135-41.

(B)
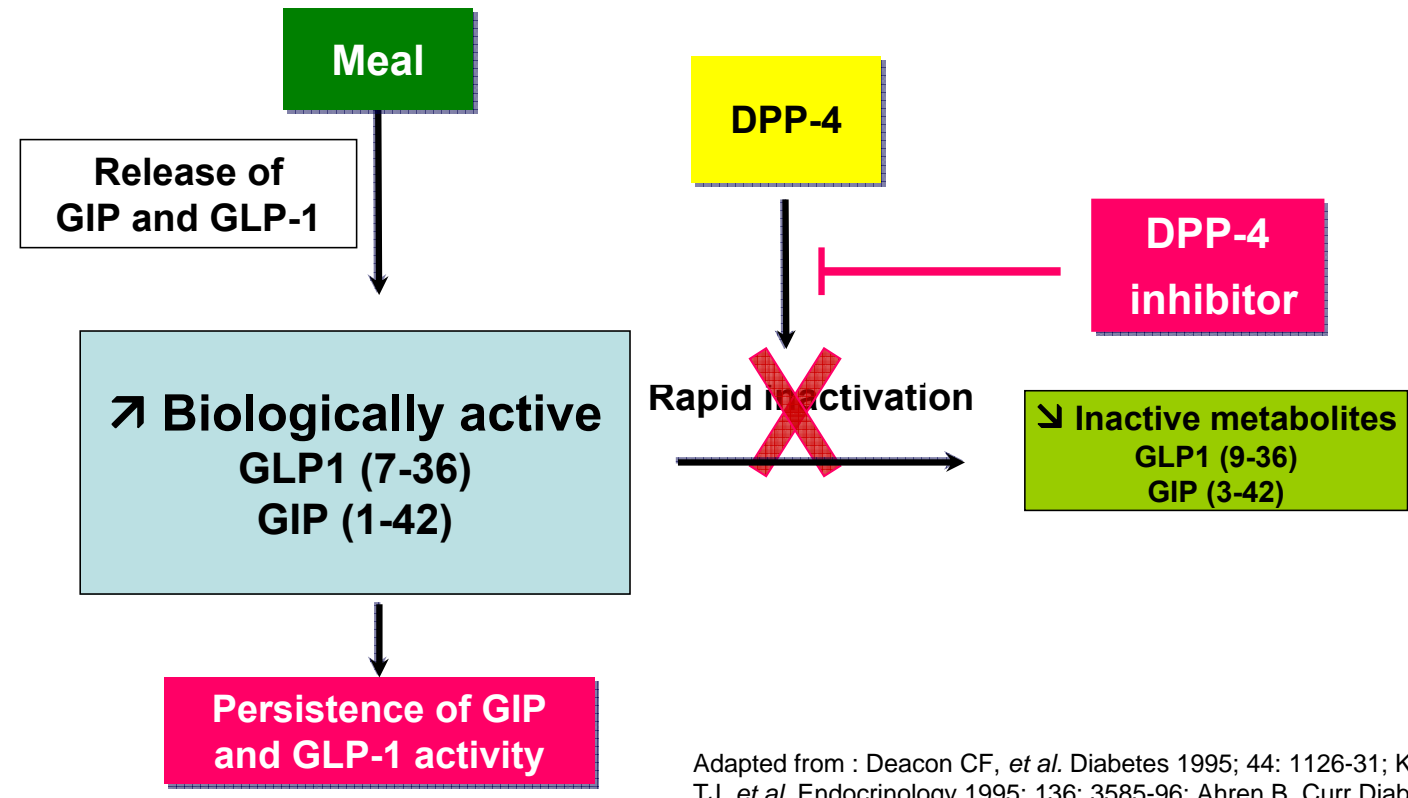

Adapted from : Deacon CF, et al. Diabetes 1995; 44: 1126-31; Kieffer TJ, et al. Endocrinology 1995; 136: 3585-96; Ahren B. Curr Diab Rep 2003; 3: 365-72; Deacon CF, et al. J Clin Endocrinol Metab 1995; 80: 952-957; Weber AE. J Med Chem 2004; 47: 4135-41.

Fig. (1). (A) Secretion and action of incretins. (B) Mechanism of action of DPP-4 and gliptins on incretin system.

immune-related cells (DPP4 is identical to CD26, a marker of activated T-cells). It is a 766 amino-acid proline peptidase which cleaves peptides after a proline residue. The human gene has been located to locus 2q24.3 on chromosome 2 [5]. It cleaves a large number of peptides in vitro, but in vivo few peptides are endogenous physiological substrates for the enzyme. Both GIP and GLP-1 are substrates for DPP-4, and genetic inactivation of the enzyme in animal results in better glucose tolerance. Pharmacological inhibition of DPP-4 results first in increased level of GIP and GLP-1, then in decreased blood glucose, via both enhanced insulin secretion and decreased glucagon release (Fig. 1B). But DPP-4 is the founding member of an enzymatic family whose members are linked by their common cleaving serine dipeptidyl peptidase mechanism. Two other human dipeptidases, DPP-8 and DPP-9, display structures closely related to DPP-4, but their precise roles remain unknown. Indeed, in animal models (rats and dogs) inhibition of DPP-8 and DPP-9 results in various tissue toxicity : splenomegaly and lymphadenopathy, gastrointestinal mortality with multiorgan pathology. Moreover, inhibition of DPP-8/9 appears to reduce T-cell activation in human in vitro models [6]. So it seems very important to assess the degree of selectivity for DPP-4 of inhibitors in clinical development: they should be highly selective for DPP-4 and unselective for DPP-8/9. 
Gliptins have no or little effect on fasting plasma lipid levels. However, it has been shown that vildagliptin can reduce postprandial triglyceride-rich lipoproteins [14].

Direct comparison is not possible between gliptins, because no head-to-head study has been performed to date.

\section{c. Sitagliptin}

Sitagliptin can fully inhibit DPP-4 at a dose range between 50 and $400 \mathrm{mg} /$ day. When used as monotherapy, a $100 \mathrm{mg}$ daily dose decreases $\mathrm{HbAlc}$ in a range of 0.60 to $0.79 \%$ ) [15]. A similar action has been found when used in combination with metformin [16] or pioglitazone [17]. Gastro-intestinal tolerance was good, there were no more hypoglycaemia with sitagliptin compared to placebo, and weight remained stable throughout the studies. In the metaanalysis performed by Amori et al. [9], HbA1c levels in the different sitagliptin studies varied from $+0.04 \%$ to $-1.05 \%$. In the seven studies comparing sitagliptin to placebo, which gathered 2404 patients, the mean change of HbAlc was $0.74 \%$. Risk ratio of adverse events (hypoglycaemia, nausea, vomiting, diarrhea, abdominal pain, cough, influenza) was not significantly different between sitagliptin and comparator.

\section{d. Vildagliptin}

After 4 weeks of treatment with $100 \mathrm{mg} / \mathrm{d}$, vildagliptin inhibits selectively DPP-4 more than $90 \%$. It is excreted by both digestive and urinary route. Its half-life is shorter than sitagliptin (1.7 vs $12 \mathrm{~h})$. Its action is yet extended in spite of this fast elimination. In monotherapy, it decreases $\mathrm{HbAlc}$ in a range of 0.4 to $1.2 \%$ vs placebo $[18,19]$. In combination therapy, the decrease of $\mathrm{HbAlc}$ was of $1.1 \%$ when vildagliptin was added to metformin [20], and of $1.0 \%$ when added to pioglitazone [21]. In the meta-analysis from Amori et al. [9], HbAlc levels in the different vildagliptin studies varied from $+0.40 \%$ to $-1.20 \%$. In the nine studies comparing vildagliptin to placebo, which gathered 1786 patients, the mean change of HbAlc was $-0.73 \%$. Vildagliptin has also been added to insulin [22]: in the combination group compared to the group given insulin alone, mean $\mathrm{HbA} 1 \mathrm{c}$ level was reduced by $0.5 \%$ vs $0.2 \%$, and hypoglycaemias were less frequent (113 events in 33 patients versus 185 events in 45 patients).

\section{e. Saxagliptin}

To date, few clinical data regarding saxagliptin are available. In a 12-week placebo-controlled trial, 338 drugnaïve type 2 diabetic patients (low-dose cohort) with inadequate glycaemic control (HbAlc between 6.5 and $9.7 \%$ ) were randomized between different doses of saxagliptin $(2.5,5,10,20$ or $40 \mathrm{mg} /$ day $)$ or placebo. Mean HbA1c level was reduced by 0.7 to $0.9 \%$, versus $0.3 \%$ for placebo. In a second cohort (high-dose cohort), 85 diabetic patients were randomized between saxagliptin $100 \mathrm{mg}$ daily and placebo for 6 weeks; HbAlc was reduced by $1.1 \%$, versus $0.4 \%$ in the placebo group. In both cohorts, weight did not significantly change compared to placebo, and incidence of confirmed hypoglycaemias was very low [23].

\section{f. Alogliptin}

When used as monotherapy in type 2 diabetic patients for 26 weeks [24], alogliptin significantly reduced HbA1c level
[-0.70\% (12.5 mg/day), $-0.91 \%(25 \mathrm{mg} /$ day $)]$, compared to patients receiving placebo $(-0.15 \%)$. The effect on weight was neutral $(12.5 \mathrm{mg} /$ day: $-0.09 \mathrm{~kg}, 25 \mathrm{mg} /$ day: $-0.22 \mathrm{~kg}$, placebo: $+0.18 \mathrm{~kg}$ ). In diabetic patients inadequately controlled on metformin monotherapy [25], mean HbAlc value was also significantly reduced (-0.6\% for both doses 12.5 and $25 \mathrm{mg}$ /day) compared to the placebo group (-0.1\%). When used in add-on to glyburide monotherapy [26], in diabetic patients, alogliptin reduced $\mathrm{HbAlc}$ levels at 26 weeks $\left[\begin{array}{lllll}-0.38 \% & (12.5 \mathrm{mg} / \text { day }), & -0.52 \% & (25 \mathrm{mg} / \text { day })\end{array}\right]$, compared to patients receiving placebo $(+0.01 \%)$. When alogliptin is added to pioglitazone therapy in type 2 diabetic patients inadequately controlled on glitazone alone or on glitazone with metformin or sulfonylurea [27], HbAlc is reduced significantly in alogliptin patients $[-0.66 \%(12.5$ $\mathrm{mg} /$ day $),-0.80 \% \quad(25 \mathrm{mg} /$ day $)]$, compared to patients receiving placebo $(-0.19 \%)$. No significant differences were found in weight. Finally, when alogliptin is added to insulin in patients with type 2 diabetes incompletely controlled on insulin alone or on insulin with metformin [28], mean $\mathrm{HbA} 1 \mathrm{c}$ level is reduced [-0.63\% (12.5 mg/day), $-0.71 \%$ (25 $\mathrm{mg} /$ day)], compared to patients receiving placebo (-0.13\%).

\section{g. Adverse Effects}

Both sitagliptin and vildagliptin appear to be welltolerated and safe, with a rate of adverse events similar to comparator. Hypoglycaemias are rare, because GLP-1 action is glucose-dependent: in the meta-analysis from Amori et al. [9], the risk of hypoglycaemia is not significantly different in patients treated with DPP-4 inhibitors vs comparators (RR 0.97 , CI 95\%: 0.50-1.86). However hypoglycaemias can be observed when a gliptin is combined with insulin or insulin secretagogue. Many studies report no effect on blood pressure, although a slight decrease has been noted in one study using vildagliptin [20]. A major topic in the use of DPP-4 inhibitors is their neutral influence on body weight. This is different from metformin, which is generally associated with slight decrease in body weight, and from the weight gain due to use of glitazones and insulin secretagogues. Studies with gliptins have reported no gastrointestinal side effect compared to placebo. Amori et al., in their meta-analysis [9], showed an increased risk of infections, such as nasopharyngitis and urinary tract infections. These observations might be explained by the ubiquity of DPP-4, which is expressed in various tissues, including immune tissues and lymphocytes. Also known as CD26 on T-cells, DPP-4 contributes to T-cell activation and proliferation. Thus it is possible that pharmacologic inhibition of DPP-4 by gliptins, especially if not selective enough, could interfere with the immune function [29].

\section{h. Potential Effects on $\beta$-Cell Function}

As the normal mass of pancreatic $\beta$-cells is tightly maintained stable between growth and apoptosis, it is critical to assess whether DPP-4 inhibitors are able to prevent or delay the decline of $\beta$-cell pancreatic function, which has been shown to progress with time in type 2 diabetes. There are experimental arguments in rodents to support that gliptins could preserve islet cell function and could improve $\beta$-cell survival, with reduced apoptosis. In streptozotocininduced diabetic mice, sitagliptin seems to preserve $\beta$-cell mass [30]; in neonatal rats, vildagliptin increases the mass 


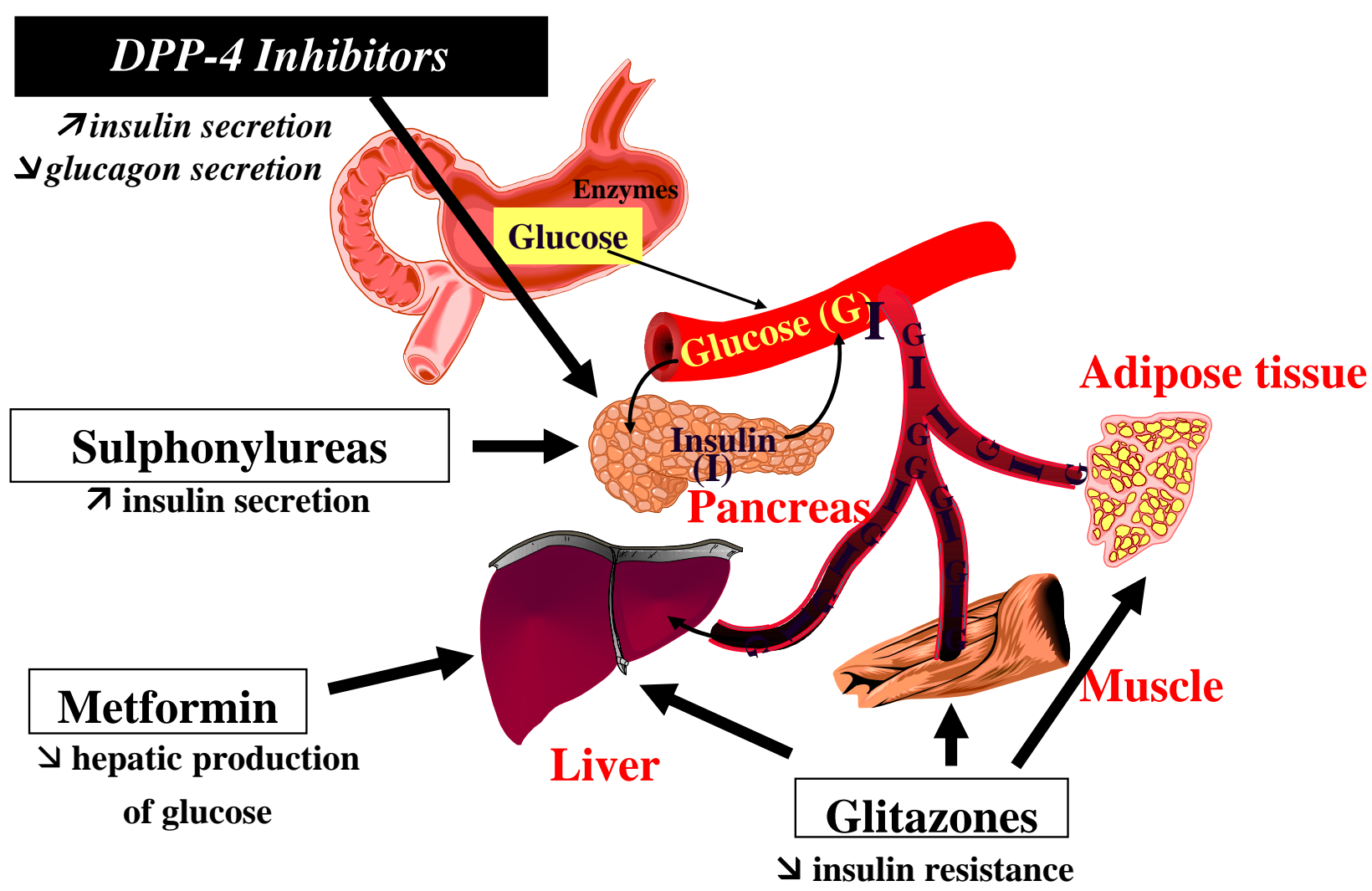

Fig. (2). Targets and mechanisms of action of oral hypoglycaemic agents.

and decrease the apoptosis of $\beta$-cell [31]. These observations deserve further confirmation in humans.

\section{Position of DPP-4 Inhibitors in the Pharmacological Management of Type 2 Diabetes}

The use of sitagliptin is now approved for the treatment of type 2 diabetes poorly controlled by diet and monotherapy, or in combination with metformin or glitazone when glycaemic control is inadequate. The recommended daily dose is $100 \mathrm{mg}$, without any adjustment according to age, hepatic insufficiency, or mild to moderate renal failure. In case of more severe renal failure, the sitagliptin dose has to be reduced to $50 \mathrm{mg} / \mathrm{d}$ if creatinine clearance ranges from 50 to $30 \mathrm{ml} / \mathrm{min}$, and to $25 \mathrm{mg}$ if clearance is less than 30 $\mathrm{ml} / \mathrm{min}$. From a broader point of view, taken into account their good tolerance, low frequence of hypoglycaemia, neutral effect on body weight, and low occurrence of drug interactions, gliptins in type 2 diabetes could replace insulin secretagogues as second or third step add-on option after first-line metformin therapy, or after second-line metforminglitazone combined treatment. They could be considered also in combination with insulin, but available data to date regarding this latter option are scarce. Although studies about combination of gliptins and sulfonylureas are going on, efficiency of such an association remains to be established, particularly concerning its cost-effectiveness and the risk of hypoglycaemia. In the ADA/EASD consensus statement [32], gliptins are not included in the algorithm for initiation and adjustment of management of hyperglycaemia, owing to their lower or equivalent overall glucose-lowering effectiveness compared with the well-validated therapies and/or to their limited clinical data or relative expense.

\section{CONCLUSION}

Treatment with DPP-4 inhibitors (gliptins) provides a new approach in the management of type 2 diabetes with oral therapy (Fig. 2). In individual studies, gliptins seem to display moderate normoglycaemic potency when compared to currently available antidiabetic drugs, but they are safe and well-tolerated, with rare hypoglycaemias, neutral effect on body weight, and no significant drug interaction. Anyway, we need further controlled studies to assess whether the potential $\beta$-cell protective property could be confirmed in the long-term, and would provide sustainable effects on glycaemic control. It will be also mandatory to watch for possible pancreatic tumorigenesis, as gliptins claim a new balanced action between stimulation of $\beta$-cell mass and reduction of apoptosis. Regarding safety issues, some uncertainty persists about eventual unfavourable side effects concerning the immune system. This concern might be overcome by increasing the selectivity for DPP-4 of commercially available inhibitors in the future.

\section{ABBREVIATIONS}

GLP-1 = Glucagon-like peptide 1

DPP-4 = Dipeptidyl peptidase 4

GIP = Glucose-dependent insulinotropic peptide

\section{REFERENCES}

[1] Perley M, Kipnis DM. Plasma insulin responses to oral and intravenous glucose: studies in normal and diabetic subjects. J Clin Invest 1967; 46: 1954-62.

[2] Holst JJ, Deacon CF, Vilsboll T, Krarup T, Madsbad S. Glucagonlike peptide-1, glucose homeostasis and diabetes. Trends Endo Metab 2008; 14: 161-8. 
[3] Barnett A. DPP-4 inhibitors and their potential role in the management of type 2 diabetes. Int J Clin Pract 2006; 60: 1454-70.

[4] Baggio LL, Drucker DJ. Biology of incretins: GLP-1 and GIP. Gastroenterology 2007; 132: 2131-57.

[5] Abbott CA, Baker E, Sutherland GR, McCaugham GW. Genomic organization, exact localization, and tissue expression of the human CD26 (DPP IV) gene. Immunogenetics 1994; 40: 331-8.

[6] Lankas GR, Leiting B, Roy RS, et al. DPP IV inhibition for the treatment of type 2 diabetes: potential importance of selectivity over dipeptidyl peptidases 8 and 9. Diabetes 2005; 54: 2988-94.

[7] Ahren B. Dipeptidyl peptidase-4 inhibitors: clinical data and clinical implications. Diabetes Care 2007; 30: 1344-50.

[8] Rosenstock J, Zinman B. Dipeptidyl peptidase-4 inhibitors and the management of type 2 diabetes mellitus. Curr Opin Endocrinol Diabetes Obes 2007; 14: 98-107.

[9] Amori RE, Lau J, Pittas AG. Efficacy and safety of incretin therapy in type 2 diabetes. Systematic review and meta-analysis. JAMA 2007; 298: 194-206.

[10] Nauck MA, Meininger G, Sheng D, Terranella L, Stein PP. Efficacy and safety of the DPP-4 inhibitor, sitagliptin, compared with the sulfonylurea, glipizide, in patients with type 2 diabetes inadequately controlled on metformin alone: a randomized, doubleblind, non-inferiority trial. Diabetes Obes Metab 2007; 9: 194-205.

[11] Rosenstock J, Baron MA, Dejager S, Mills D, Schweizer A. Comparison of vildagliptin and rosiglitazone monotherapy in patients with type 2 diabetes: a 24-week, double blind, randomized trial. Diabetes Care 2007; 30: 217-23.

[12] Rosenstock J, Baron MA, Camisasca RP, Cressier F, Couturier A, Dejager S. Efficacy and tolerability of initial compbination therapy with vildagliptin and pioglitazone compared with the component monotherapy in patients with type 2 diabetes. Diabetes Obes Metab 2007; 9: 175-85.

[13] Schweizer A, Couturier A, Foley JE, Dejager S. Comparison between vildagliptin and metformin to sustain reductions in $\mathrm{HbA} 1 \mathrm{c}$ over 1 year in drug-naïve patients with type 2 diabetes. Diabet Med 2007; 24: 955-61.

[14] Matikainen N, Manttäri S, Schweizer A, et al. Vildagliptin therapy reduces postprandial intestinal triglyceride-rich lipoprotein particles in patients with type 2 diabetes. Diabetologia 2006; 49: 2049-57.

[15] Raz I, Hanefeld M, Xu L, Caria C, Williams-Herman D, Khatami H. Sitagliptin Study 023 group. Efficacy and safety of the dipeptidyl peptidase-4 inhibitor sitagliptin as monotherapy in patients with type 2 diabetes mellitus. Diabetologia 2006; 49: 256471.

[16] Charbonnel B, Karasik A, Liu J, Wu M, Meininger G. Sitagliptin Study 020 group. Diabetes Care 2006; 29: 2638-43.

[17] Rosenstock J, Brazg R, Andryuk PJ, Lu K, Stein P. Sitagliptin Study 019 group. Efficacy and safety of the dipeptidyl peptidase-4 inhibitor sitagliptin added to ongoing pioglitazone therapy in patients with type 2 diabetes mellitus :a 24-week muticenter randomized double-blind placebo-controlled parallel-group study. Clin Ther 2006; 28: 156-68.
[18] De Jager S, Razac S, Foley JE, Schweizer A. Vildagliptin in drugnaïve patients with type 2 diabetes: a 24 -week, double-blind, randomized, placebo-controlled, multiple-dose study. Horm Metab Res 2007; 39: 218-23.

[19] Ristic S, Byiers S, Foley JE, Holmes D. Improved glycemic control with DPP-4 inhibition in patients with type 2 diabetes: vildagliptin dose response. Diabetes Obes Metab 2005; 7: 692-8.

[20] Bosi E, Camisasca RP, Collober C, Rochotte E, Garber AJ. Effects of vildagliptin on glucose control over 24 weeks in patients with type 2 diabetes inadequately controlled with metformin. Diabetes Care 2007; 30: 890-5.

[21] Garber AJ, Schweizer A, Baron MA, Rochotte E, Dejager S. Vildagliptin in combination with pioglitazone improves glycaemic control in patients with type 2 diabetes failing thiazolidinedione monotherapy. Diabetes Obes Metab 2007; 9: 166-74.

[22] Fonseca V, DeJager S, Albrecht D, Shirt L, Schweizer A. Vildagliptin as add-on to insulin in patients with type 2 diabetes. Diabetes 2006; 55 (suppl 1): A111.

[23] Rosenstock J, Sankoh S, List JF. Glucose-lowering activity of the dipeptidyl peptidase-4 inhibitor saxagliptin in drug-naïve patients with type 2 diabetes. Diabetes Obes Metab 2008; 10: 376-86.

[24] De Fronzo R, Fleck P, Wilson C, Mekki Q. Alogliptin monotherapy improves glycemic control in patients with type 2 diabetes. Diabetes 2008; 57 (suppl 1): A133; abstract no. 446 P.

[25] Nauck M, Ellis G, Fleck P, Wilson C, Mekki Q. Efficacy and safety of alogliptin added to metformin therapy in patients with type 2 diabetes. Diabetes 2008; 57: A142.

[26] Pratley R, Kipnes M, Fleck P, Wilson C, Mekki Q. Alogliptin added to sulfonylurea therapy in patients with type 2 diabetes reduces $\mathrm{HbAlc}$ without increasing hypoglycaemia. Diabetes 2008; 57: A133; abstract no. 445 P.

[27] Pratley R, Reusch J, Fleck P, Wilson C, Mekki Q. Efficacy and safety of alogliptin added to pioglitazone therapy in patients with type 2 diabetes. Diabetes 2008; 57: A143.

[28] Rosenstock J, Rendell M, Gross J, Fleck P, Wilson C, Mekki Q. Alogliptin added to insulin therapy in patients with type 2 diabetes reduces $\mathrm{HbAlc}$ without increasing weight gain or hypoglycaemia. Diabetes 2008; 57: A132.

[29] Drucker DJ, Nauck MA. The incretin system: glucagon-like peptide-1 receptor agonists and dipeptidyl peptidase-4 inhibitors in type 2 diabetes. Lancet 2006; 368: 1696-705.

[30] Mu J, Woods J, Zhou YP, et al. Chronic inhibition of dipeptidyl peptidase-4 with a sitagliptin analog preserves pancreatic beta-cell mass and function in a rodent model of type 2 diabetes. Diabetes 2006; 55: 1695-704.

[31] Duttaroy A, Voelker F, Merriam K, Zhang X, Ren X, Burkey B. The DPP-4 inhibitor vildagliptin increases pancreatic beta cell neogenesis and decreases apoptosis. Diabetes 2005; 54: A141.

[32] Nathan DN, Buse JB, Davidson MB, et al. Medical management of hyperglycemia in type 2 diabetes: a consensus algorithm for the initiation and adjustment of therapy. A consensus statement of the American Diabetes Association and the European Association for the Study of Diabetes. Diabetes Care 2009; 32: 193-203. 